\title{
Long-term peatland dynamics and effects of peatland-mediated feedbacks on the climate system
}

\author{
Nitin Chaudhary
}

\section{The individual- and patch-based peatland-vegetation model LPJ-GUESS was employed to study past and future peatland carbon dynamics across the pan-Arctic. A substantial reduction in peatland sink capacity, expected under rapid global warming, has the potential to trigger important climate feedlbacks.}

Peatlands are important carbon reserves in the terrestrial ecosystem and cover $3 \%$ of the terrestrial land surface area $\left(3.7 \times 10^{6} \mathrm{~km}^{2}\right.$. Bridgham et al. 2006, Hugelius et al. 2020) Peatlands store around 400-600 petagrams $\left(10^{15} \mathrm{~g}\right)$ of carbon $(\mathrm{PgC})$ since the Holocene and comprise around $30 \%$ of the presentday soil organic carbon pool (Yu et al. 2010; Hugelius et al. 2020). They are also a major source of atmospheric methane emissions (Abdalla et al. 2016). A significant fraction of peatland area coincides with permafrost, affecting carbon accumulation rates and biogeochemical processes (Obu et al. 2019). The majority of northern peatlands started developing 8000-12,000 years ago as a result of the availability of new land surface following deglaciation, warmer climate conditions, higher summer insolation, more pronounced seasonality, elevated greenhouse gas emissions, and higher moisture conditions (MacDonald et al. 2006). However, present-day distribution of soil organic carbon is not uniform across the pan-Arctic region $\left(45-75^{\circ} \mathrm{N}\right)$ due to differential peat initiation periods, bulk density values, and changes in dominant plant types (Loisel et al. 2014). Recent advances in field measurements have reduced some uncertainties related to carbon accumulation rates and peat depth across the pan-Arctic (Loisel et al. 2014). However, due to the large extent of peatlands, calculating global and regional estimates directly from field measurements would be difficult. This difficulty can be circumvented by employing peatland models, as these simulate realistic peatland carbon accumulation rates at larger spatial and temporal scales and can further strengthen the recent progress on observing carbon accumulation rates (Stocker et al. 2014; Chaudhary et al. 2017a, b). Understanding long-term peatland carbon dynamics and their controls are crucial for predicting their role in moderating future climate.

\section{Dynamic peatland-vegetation models} and long-term carbon dynamics

Dynamic global vegetation models (DGVMs) such as LPJ-GUESS (Lund-Potsdam-Jena General Ecosystem Simulator) are used to understand the changes in vegetation, carbon cycle, and climate feedbacks on different temporal and spatial scales. They provide a suitable platform to study longterm peatland carbon dynamics, enabling us to understand the role of peatlands in past and future climate conditions. To this end, a recent study demonstrated a new implementation of peatland and permafrost dynamics with the unique representation of spatial heterogeneity in the dynamic global vegetation model (in LPJ-GUESS; Chaudhary et al. 2017a). This was the first time that any model included dynamic annual multi-layer peat accumulation, freezing-thawing cycles, lateral flow, and spatial heterogeneity in the framework of a dynamic vegetation model (Chaudhary et al. 2017a), and was applied at local to regional spatial scales.

The current model scheme consists of many key variables and interactions controlling the non-linear peatland dynamics (Chaudhary et al. 2018). The relationship between the average rate of peat formation and water table position (Belyea 2009), cyclicity among micro-formations (hummocks and hollows) (Heikki 2002), internal eco-hydrological feedbacks, and multi-directionality (Belyea 2009) that have frequently been observed in many peatland sites can be simulated and explained using this detailed model scheme. The model has been applied in different regions in the Northern Hemisphere and shown to reproduce peat accumulation, permafrost dynamics, and vegetation distribution realistically in several Scandinavian sites (Chaudhary et al. 2017a).

\section{Changes in peatland carbon stocks in the future}

Peatlands are severely threatened by ongoing anthropogenic climate warming, and it is expected that many peatland regions will experience significant changes in their
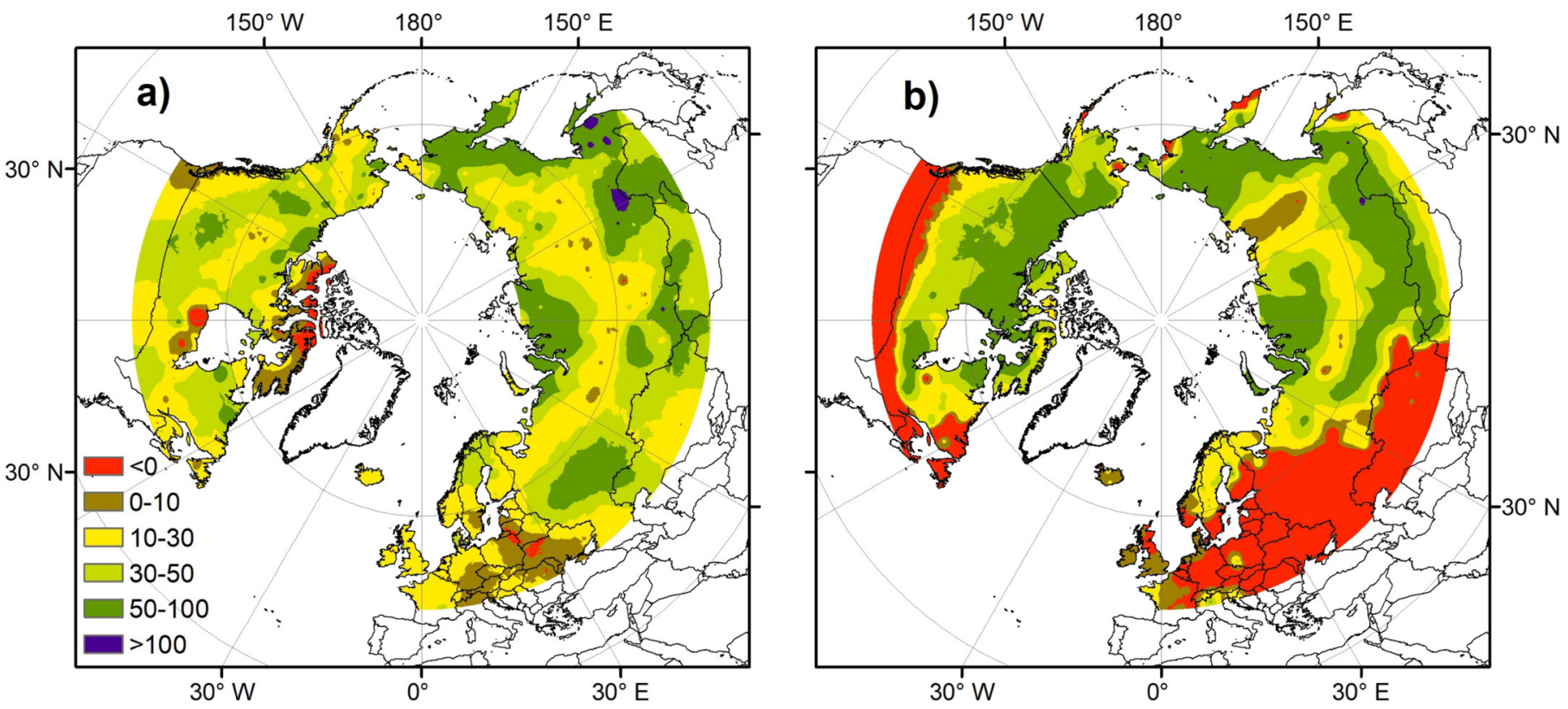

Figure 1: Modeled net peatland carbon accumulation rates (in $\mathrm{gC} \mathrm{m} \mathrm{m}^{2} / \mathrm{yr}$ ) across the pan-Arctic (A) at present (1991-2000) and (B) at the end of the century (2091-2100).

Positive values indicate carbon sinks, and negative values represent sources of carbon from peatlands to the atmosphere (Chaudhary et al. 2020). 


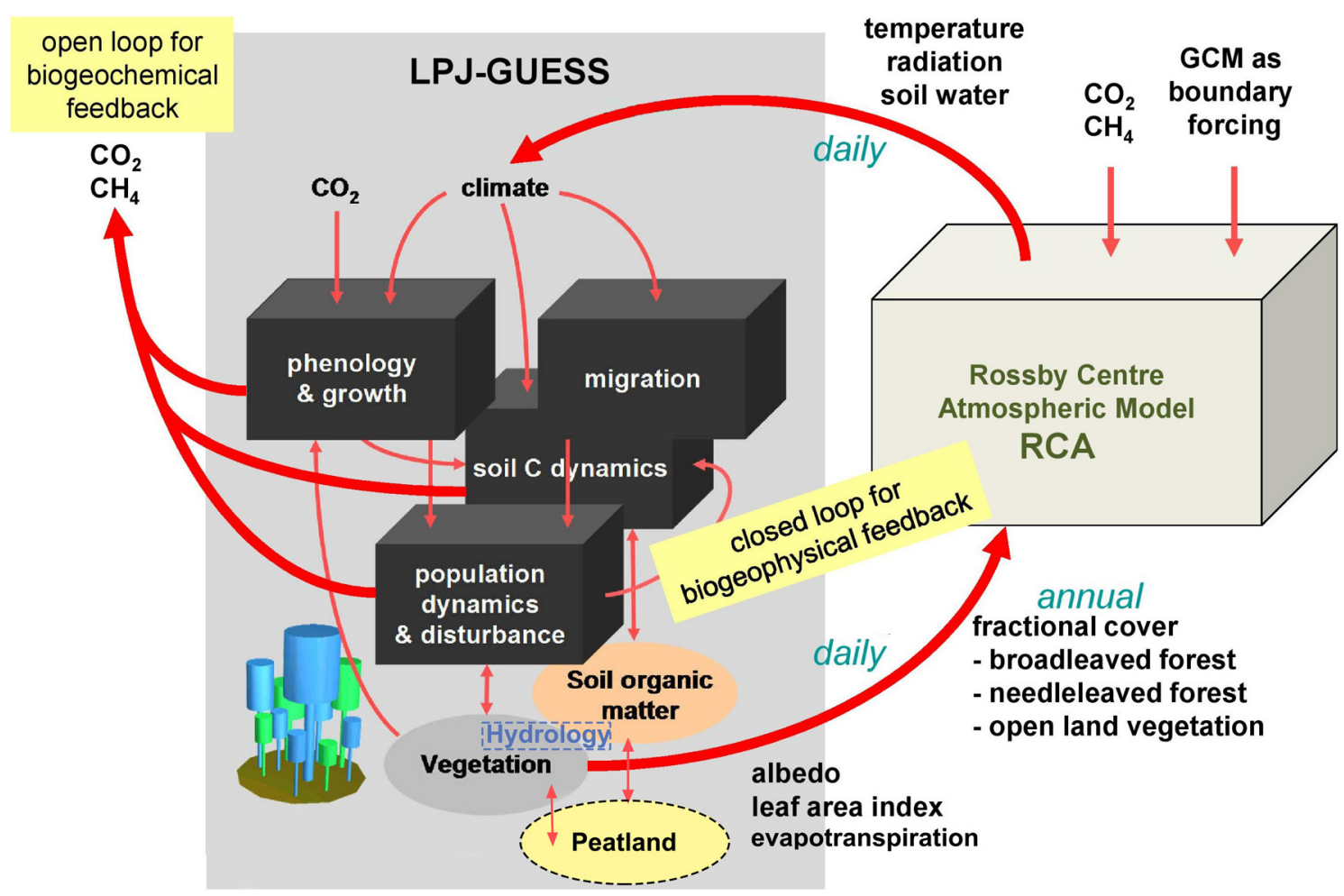

Figure 2: A proposed schematic representation of the regional Earth system model RCA-GUESS.

carbon fluxes in the near future. Subsequent regional (pan-Arctic) studies employing the model described above (Chaudhary et al. 2017b; 2020) found that many peatland regions in Europe, including Scandinavia and Russia, and central and eastern Canada would change from carbon sinks to potential carbon sources in the coming century, while other sites would enhance their sink capacity at other sites (Fig. 1). It was found that permafrost peatlands are likely to accumulate more peat in warmer conditions due to the high level of moisture that results from permafrost thaw, higher precipitation, and elevated $\mathrm{CO}_{2}$ levels. On the other hand, peatlands that experience reduced precipitation rates and are devoid of underlying permafrost will lose more carbon in the future, particularly peatlands located in the European region and peatlands between $45^{\circ}$ and $55^{\circ} \mathrm{N}$. Overall, the study showed that peatlands would continue to act as carbon sinks, but their sink capacity will be substantially reduced under rapid global warming (Fig. 1b) in the coming decades.

\section{Peatland-mediated feedbacks}

The rapid, ongoing changes in many peatland areas due to climate change have the potential to disturb the prevailing landatmosphere carbon balance and trigger some pertinent climate-relevant feedbacks. The higher carbon emissions from peatlands as a result of climate warming could result in a positive feedback on climate change, thus amplifying warming (Baird et al. 2009; Frolking et al. 2009). On the other hand, elevated $\mathrm{CO}_{2}$ concentrations in the atmosphere together with an increase in moisture conditions due to permafrost thawing and higher precipitation rates could promote plant growth and peat accumulation (Loisel and Yu 2013). This, in turn, may enhance the carbon (i.e. $\mathrm{CO}_{2}$ ) uptake capacity of many peatlands and would be expected to result in a negative feedback on climate warming. In addition, an increase in the active layer depth or soil moisture due to temperaturedriven permafrost degradation and structural collapse of many peatland sites located in cold environments could lead to the formation of wet and water-filled areas (Belyea 2009; Turetsky et al. 2019). This would most likely result in higher methane emissions that would further accelerate regional warming. However, the net effect of all these competing peatland-mediated feedbacks is difficult to study in isolation. For that, an integrated study is required that takes all the critical interactions and feedbacks between peatland carbon cycle and climate into account.

\section{Integrating peatland dynamics in Earth system models}

Contemporary Earth system models simulate the state of the atmosphere and biosphere at different spatial and temporal scales and predict their responses and behavior in rapidly changing climate conditions. However, these advanced models currently lack peatlands as a distinct land surface type (Frolking et al. 2009). Due to the absence of a comprehensive representation of detailed peatland and cryospheric processes in any of the current Earth system models, our understanding of these hypothesized peatland-mediated feedbacks on regional and global scales is limited. The peatland dynamics in LPJ-GUESS seem to be reasonable, as the model produces realistic carbon accumulation rates and permafrost distribution at different spatial and temporal scales (Chaudhary et al. 2020). With this peatland extension, the coupled regional Earth system model (RCA-GUESS) will be appropriate for addressing questions related to short-term and long-term effects of peatland dynamics on regional climate (Fig. 2). The model will be employed in the pan-Arctic region to quantify the magnitude, direction, and strengths of peatland carbon-climate feedbacks; these results will then be fed into the land-surface module of the global Earth system model to improve global peatland modeling.

\section{AFFILIATIONS}

Department of Physical Geography and Ecosystem Science, Lund University, Sweden

Department of Geosciences, University of Oslo, Norway

\section{CONTACT}

Nitin Chaudhary: nitin.chaudhary@nateko.lu.se, nitin.chj@gmail.com

\section{REFERENCES}

Abdalla M et al. (2016) Ecol Evol 6: 7080-7102 Baird AJ et al. (2009) In: Baird AJ et al. (Eds) Carbon Cycling in Northern Peatlands. American Geophysical Union, 1-3

Belyea LR (2009) In: Baird AJ et al. (Eds) Carbon Cycling in Northern Peatlands. American Geophysical Union, 5-18

Bridgham SD et al. (2006) Wetlands 26: 889-916 Chaudhary N et al. (2017a) Biogeosciences 14: 2571-2596 Chaudhary N et al. (2017b) Biogeosciences 14: 4023-4044

Chaudhary N et al. (2018) Ecosystems 21: 1196-1214 Chaudhary N et al. (2020) Global Change Biol 26: 4119-4133

Frolking S et al. (2009) In: Baird AJ et al. (Eds) Carbon Cycling in Northern Peatlands. American Geophysical Union, 19-35

Heikki S (2002) Fennia Int J Geogr 180: 43-60

Hugelius G et al. (2020) Proc Natl Acad Sci USA 117 20438-20446

Loisel J, Yu Z (2013) J Geophys Res Biogeosci 118: 41-53 Loisel J et al. (2014) Holocene 24: 1028-1042 MacDonald GM et al. (2006) Science 314: 285-288 Obu J et al. (2019) Earth-Sci Rev 193: 299-316 